\title{
Synopsis of Bradepyris Kieffer, 1905 (Hymenoptera, Bethylidae, Mesitiinae)
}

\author{
Diego N. BARBOSA ${ }^{1, *} \&$ Celso O. AZEVEDO ${ }^{2}$ \\ ${ }^{1,2}$ Universidade Federal do Espírito Santo, Departamento de Biologia, Av. Fernando Ferrari 514, \\ Goiabeiras, 29.075-910, Vitória ES, Brazil. \\ *Corresponding author: mesitiinae@gmail.com \\ ${ }^{2}$ E-mail: bethylidae@gmail.com \\ ${ }^{1}$ urn:1sid:zoobank.org:author:95D76114-BF6C-4715-881B-10F7B2ACD2D0 \\ ${ }^{2}$ urn:lsid:zoobank.org:author:CD98B489-7611-4A33-AF53-3016B9DA1617
}

\begin{abstract}
Two new junior synonyms, Pseudomesitius Duchaussoy, 1916 syn. nov. and Triglenus Marshall, 1905 syn. nov., for the genus Bradepyris Kieffer, 1905 are proposed and a new diagnosis for the genus is given. Two new species (based on males) from the Saharo-Arabian region are here described: Bradepyris jordanicus, sp. nov. and B. baleariensis, sp. nov. A brief revision, with a key to the males and females of all species of this genus, and the first male genitalia descriptions are also provided.
\end{abstract}

Key words. Synonym, new species, genitalia description, key, new records.

Barbosa D.N. \& Azevedo C.O. 2015. Synopsis of Bradepyris Kieffer, 1905 (Hymenoptera, Bethylidae, Mesitiinae). European Journal of Taxonomy 151: 1-16. http://dx.doi.org/10.5852/ejt.2015.151

\section{Introduction}

The Magyar Természettudományi Múzeum, in Budapest, Hungary, has the most important collection of Bethylidae, particularly of the subfamily Mesitiinae, in the world. Major efforts to accumulate this collection were made by László Móczár, who worked at this institution for decades. While visiting this museum, two male specimens of Mesitiinae from the Mediterranean region, one from Jordan and the other from the Baleares Islands (Spain), drew our attention.

These two specimens have an unusual combination of characters that suggested a relationship with Bradepyris Kieffer, 1905, Pseudomesitius Duchaussoy, 1916 or Triglenus Marshal, 1905, depending on the character cluster we analyzed. In other words, these three genera have common characters, and we were not able to classify these specimens.

Given this scenario, we decided to work on the taxonomic boundaries of these three genera in order to establish the generic assignment of the two male specimens cited above. To this purpose we analyzed all described species of these three genera in order to generate a synopsis. As a result, we provide two new junior synonyms, a key to the males and females of species of Bradepyris, and the first male genitalia descriptions. 


\section{Material and methods}

The material examined was provided by:

BMNH $=$ The Natural History Museum, London, England (David Notton)

$\mathrm{CNCI}=$ Canadian National Collection of Insects, Ottawa, Canada (John Huber)

HNHM = Magyar Természettudományi Múzeum, Budapest, Hungary (Zoltán Vas)

MNHN = Muséum National d'Histoire Naturelle, Paris, France (Claire Villemant)

The diagnoses of species whose types or voucher specimens were lost are based on information from the literature.

The terminology of body structures generally follows Barbosa \& Azevedo (2009, 2011), DuPorte (1965), Evans (1964), Gibson (1986), Mikó et al. (2007), Móczár (1970), Richards (1977) and Ronquist \& Nordlander (1989).

The descriptions and key were generated with DELTA (Descriptive Language for Taxonomy), according to Dallwitz et al. (1993).

Figs 1-3 were made using a Leica MZ80 Stereo Microscope. Images were obtained with a Leica MD2500 Microscope magnifying glass attached to a Leica DFC 495 video camera using Leica LAS (Leica Application Suite V3.6.0) Microsystems by Leica (Switzerland) Ltd, and combined using Helicon Focus (version 4.2.9) and the rendering method based on Method C (Pyramid). All illustrations and plates were enhanced by using adjustments (e.g., levels, shadows/highlights), tools (e.g., healing brush, clone stamp) and filters (e.g., unsharp mask).

The genera of Mesitiinae were identified using the key provided by Argaman (2003).

\section{Abbreviation \\ LFW = length of forewing \\ $\mathrm{VOL}=$ vertex-ocular line in dorsal view}

\section{Results}

\section{Taxonomic descriptions}

Class Hexapoda Blainville, 1816

Order Hymenoptera Linnaeus, 1758

Suborder Apocrita Latreille, 1810

Superfamily Chrysidoidea Linnaeus, 1761

Family Bethylidae Latreille, 1802

Subfamily Mesitiinae Kieffer, 1914

\section{Bradepyris Kieffer, 1905}

Fig. 1A-F

Bradepyris Kieffer, 1904-1906: 29, 101.

Pseudomesitius Duchaussoy, 1916: 113-114. Type species: Pseudomesitius validithorax Duchaussoy, 1916 by original designation. Syn. nov.

Triglenus Marshall, 1905: 250, 372. Type species: Triglenus numidus Marshall, 1906 (in Kieffer \& Marshall 1904-1906) by original designation. Syn. nov. 
BARBOSA D.N. \& AZEVEDO C.O., Synopsis of Bradepyris Kieffer, 1905
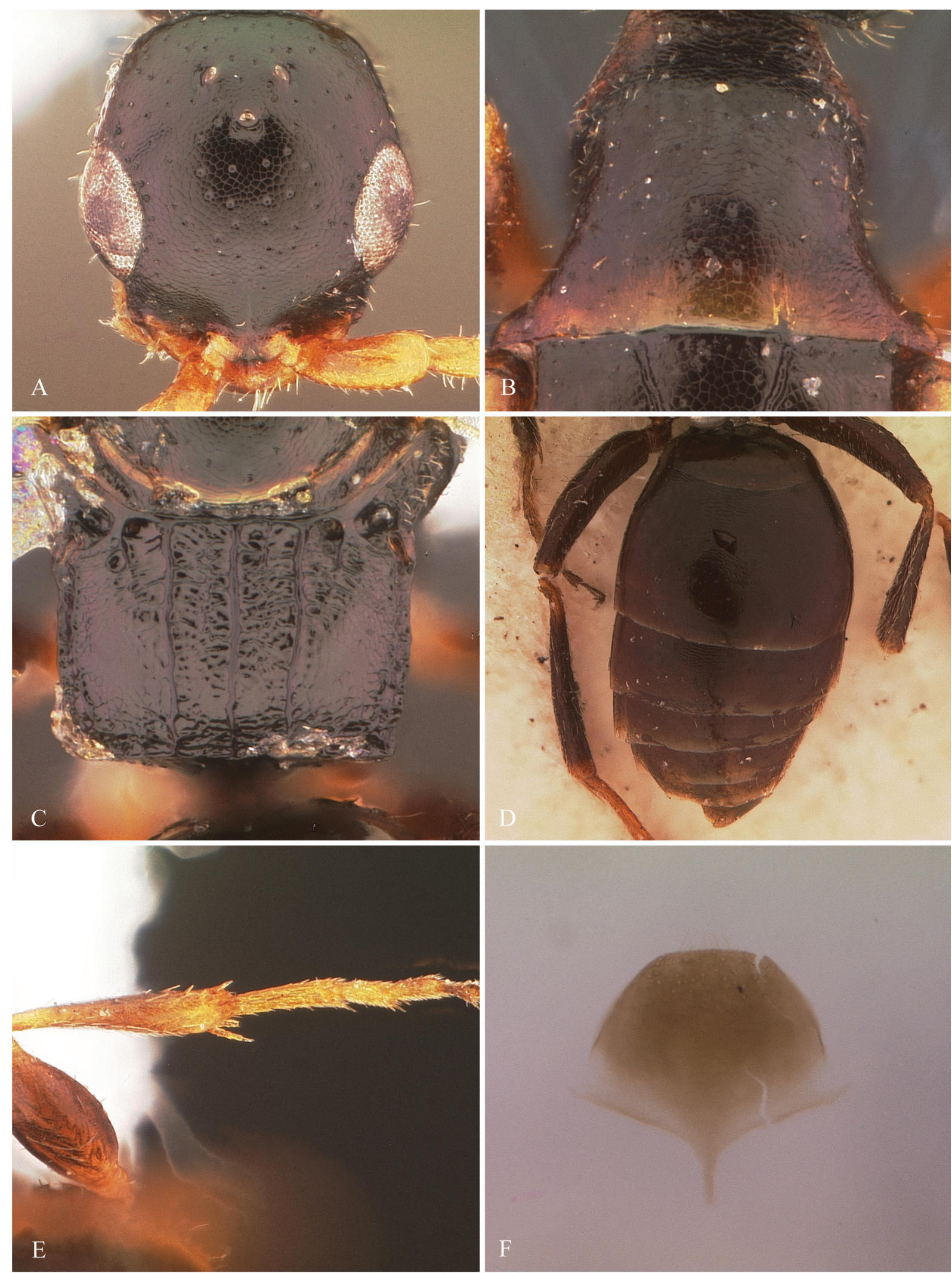

Fig. 1. Diagnostic characters of Bradepyris. A. Head in dorsal profile. B. Pronotal disc. C. Propodeal disc. D. Metasoma in dorsal profile. E. Mesotibia. F. Hypopygium. 


\section{Type species}

Bradepyris apterus Kieffer, 1906 by original designation.

\section{Remarks}

1. In the original description, the genus was cited and characterized in the key and the type species was designated, but neither the genus nor the type species were described.

2. Kieffer (1905) proposed the genus Bradepyris to accommodate a single species, B. apterus Kieffer, 1905, whose type was an apterous female specimen, with propodeal disc without median carina. Argaman (2003) redefined and redescribed the genus as having the head longer than wide, the propodeal disc without lateral carina, a short forewing, and the mesotibia with distal spines. The lateral carina of the propodeal disc is always present in species of Bradepyris, and the three other characters are found in several other genera within the Mesitiinae. This means, that the cited characters do not suffice to define this genus.

3. Marshall (1905) proposed Triglenus to accommodate T. numidus Marshall, based on a female specimen from Algeria. Argaman (2003) redefined the genus and described it as having the propodeal disc with lateral carina, a fully developed forewing, and the first metatarsomere with distal spines. The two former characters are found in many other genera of the Mesitiinae, and the latter one is found in only one species of Triglenus. This means, that the cited characters cannot be used to define this genus either.

4. Duchaussoy (1916) proposed Pseudomesitius to accommodate P. validithorax Duchaussoy, based on female specimen from Algeria and Morroco. Argaman (2003) redefined the genus and described it as having the head longer than wide, the propodeal disc with lateral carina, a fully developed forewing, and the first metatarsomere with distal spines. The three former characters are found in Bradepyris (see above) and the latter one in Triglenus. Once again, the cited characters cannot be used to define this genus.

Based on these descriptions, it can be concluded that the characters of the three genera are overlapping, with a large intrageneric variability. Therefore, we conclude that they correspond to only one genus, and we consider Pseudomesitius and Triglenus to be junior synonyms of Bradepyris, which is diagnosed below.

\section{Diagnosis}

Head (Fig. 1A) longer than wide. Pubescent eye. Ocellar elevation present. Pronotal disc (Fig. 1B) without longitudinal sulcus. Mesopleuron with anterior fovea. Propodeum (Fig. 1C) with inner discal carina parallel to median carina, posterior spine absent or hardly distinct. Forewing with nebulous $3 \mathrm{C}$ vein. Hind wing with long Sc+R vein; long A vein. Mesotibia (Fig. 1E) usually with distal spines. Metasoma (Fig. 1D) with tergite II coriaceous. Hypopygium (Fig. 1F) unilobate. Genitalia with dorsal arm of paramere longer than ventral arm.

Under this scenario, we were able to find seven species in four other genera of the Mesitiinae (including Triglenus and Pseudomesitius) and, surprisingly, also one species in a genus of the Epyrinae which correspond to the diagnosis above. Hence, the following species are newly referred to Bradepyris:

B. dimorphus (Kieffer, 1911) comb. nov. (from Pseudomesitius)

B. fuscipennis (Kieffer, 1906) comb. nov. (from Triglenus)

B. levis (Móczár, 1986) comb. nov. (from Clytrovorus)

B. numidus (Marshall, 1906) comb. nov. (from Triglenus)

B. pardoi (Móczár, 1984) comb. nov. (from Anaylax)

B. proximus (Kieffer, 1906) comb. nov. (from Rhabdepyris)

B. suarezi (Móczár, 1984) comb. nov. (from Clytrovorus) 
BARBOSA D.N. \& AZEVEDO C.O., Synopsis of Bradepyris Kieffer, 1905

B. validithorax (Duchaussoy, 1916) comb. nov. (from Pseudomesitius)

\title{
Distribution
}

This genus is Palaearctic and confined to the Mediterranean region (Spain, Baleares Islands, Gibraltar, Morocco, Algeria, Tunisia, Israel and Jordan).

Bradepyris jordanicus sp. nov. urn:1sid:zoobank.org:act:E722E37D-4460-45A6-B2C6-1A60C3CAB951

\author{
Figs $2 \mathrm{~A}-\mathrm{D}, 4 \mathrm{~A}-\mathrm{C}$
}

\section{Diagnosis}

Head longer than wide; malar space shorter than vertex-ocular line; clypeus with median lobe quadrate, with median clypeal carina inclined in lateral profile; antenna with sparse and long pubescence, flagellomeres long; frons not foveolate; narrow ocellar fovea present. Mesosoma coriaceous; pronotal disc with anterior corner rounded, side slightly concave, posterior margin straight; mesoscutum shorter than mesoscutellum. Propodeal disc with longitudinal ridge between median and inner discal carinae. Mesopleuron coriaceous; posterior foveolate, complete oblique sulcus present. Forewing with nebulous $3 \mathrm{Cu}$ and $2 \mathrm{~A}$ vein absent. Metasoma with hypopygium wider than long, with anterior corner angulate. Genitalia with dorsal arm of paramere longer than ventral arm, "S"-shaped, and with basal margin narrow; ventral arm slender, with apex densely hairy, and inner margin straight; cuspis with arms slightly indistinct; aedeagus slender and not reaching paramere apex level, with apical margin rounded, apodema divergent, base curved laterad.

\section{Etymology}

The specific epithet jordanicus refers to the provenance of the material.

\section{Material examined}

Holotype

JORDAN: §̂, Wadi Sir, 600 m, 20 Apr. [19]56, J. Klapperich col. (HNHM).

\section{Description}

Body (Fig. 2A). $3.15 \mathrm{~mm}$ long. LFW $1.84 \mathrm{~mm}$.

Colours. Head dark and mesosoma dark castaneous, nearly black, except pronotum dark castaneous; antenna, mandible and palpi light castaneous; tegula and legs dark castaneous, except tarsi light castaneous; wings sub-hyaline with wing venation dark castaneous; metasoma dark castaneous.

HEAD (Fig. 2B). Head longer than wide, narrow in lateral profile. Malar space shorter than vertex-ocular line, one parallel to the other in dorsal profile. Mandible wide apically, lower margin curved, with four sharpened apical teeth, lower tooth longer than immediately upper teeth, and wider than others. Palpi caliciform, and cylindrical in cross section. Clypeus with median lobe delimitated, quadrate, lateral lobe absent; median clypeal carina inclined in lateral profile, complete, line-shaped in dorsal profile, and below torulus. Antennal foraminal distance less than antennal foramen diameter. Antenna with conspicuous pubescence, erect, sparse, and long; scape slightly curved, with same diameter across extension; pedicel longer than wide, caliciform; flagellomeres long; first flagellomere as long as pedicel, as long as others. Eye small, round, glabrous, with contour even. Frons not foveolate. Ocellar triangle not compact, placed on posterior half of head; frontal angle of ocellar triangle right; ocellar fovea present and narrow; ocelli very small. Vertex convex. Dorsal and ventral half of occipital carina high, with side striate. 

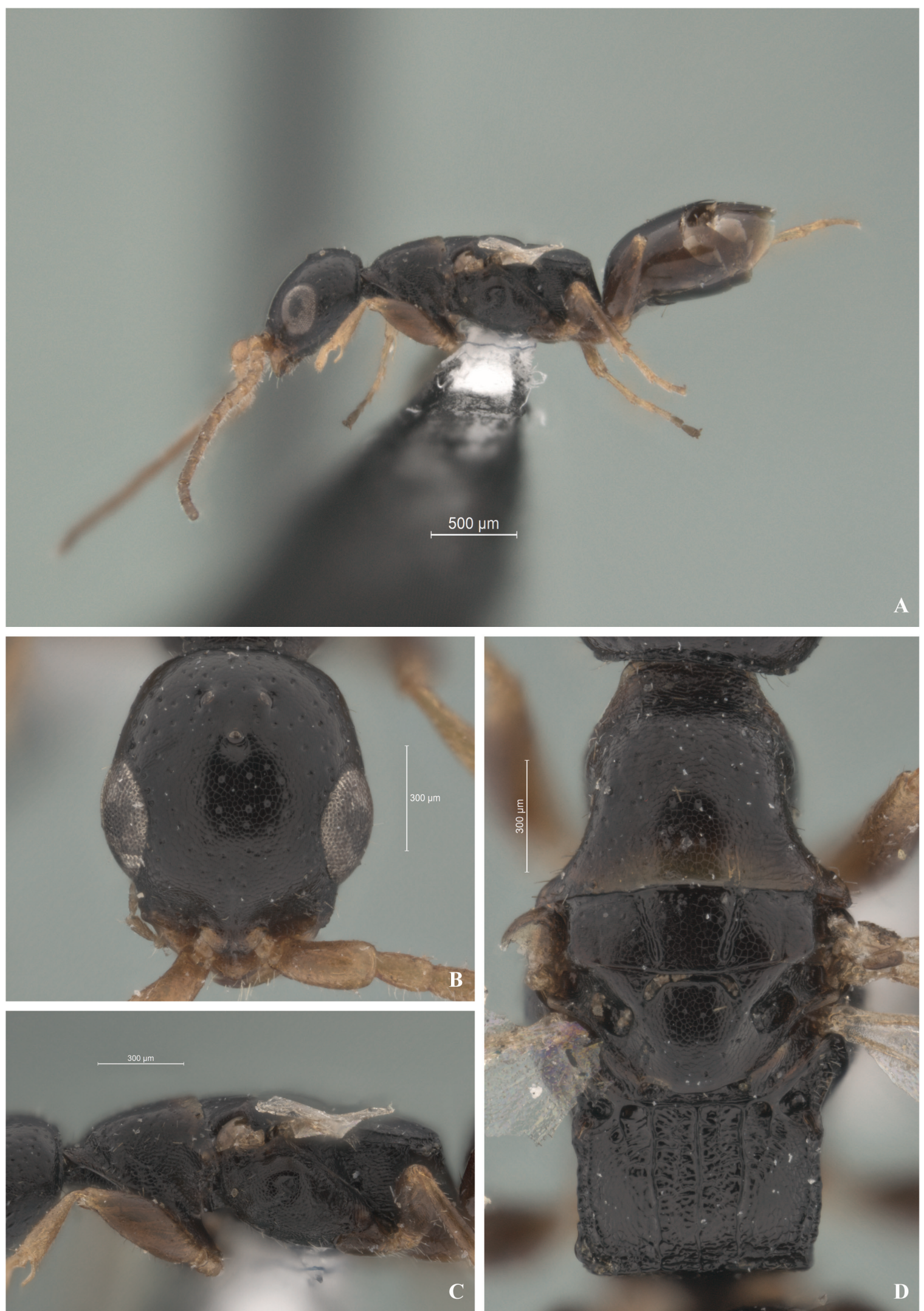

Fig. 2. Bradepyris jordanicus sp. nov. Holotype, ô. A. Lateral habitus. B. Head in dorsal profile. C. Mesosoma in lateral profile. D. Mesosoma in dorsal profile. 
Mesosoma (Fig. 2C-D). Pronotum with anterior slope inclined in lateral profile; pronotal plate not foveolate, without plate sulcus; pronotal disc as long as wide, coriaceous, trapezoidal, with anterior margin convex, anterior corner rounded, side slightly concave, without longitudinal pronotal sulcus, and posterior margin straight. Mesoscutum coriaceous and shorter than mesoscutellum; longitudinal mesoscutal sulcus absent. Notaulus complete, shallow, narrow, and polished. Parapsidal signum incomplete, shallow, and parallel. Axilla polished and shallow. Mesoscutum-mesoscutellar sulcus inconspicuous. Mesoscutellar sulcus narrow, arched, not dilated at ends, and fused with axilla. Mesoscutellum longer than wide, coriaceous, and touching propodeal disc. Metanotum overlapping lateral region of mesoscutellum. Propodeal disc $1.5 \times$ as long as wide medially, with central fovea fused with propodeal triangle fovea, with three carinae, median carina complete, with longitudinal ridge between median and inner discal carinae, sublateral and inner discal carina not fused anteriorly, inner discal carina complete, with sublateral carina, with lateral carina, posterior carina complete; spiracle elliptical; posterior spine absent. Declivity of propodeum coriaceous, with median carina and without lateral carina. Lateral surface of propodeum coriaceous, without upper and posterior carina. Mesopleuron coriaceous; acropleural sulcus continuous with mesopleural suture; posterior oblique sulcus present, foveolate, and complete; mesopleural suture with inner margin striate. Propleuron with epicoxal sulcus shallow and polished. Pleurosternum with epicoxal sulcus polished.

WINGS. Forewing with $\mathrm{C}$ cell very narrow and longitudinally folded; $\mathrm{R}$ cell shorter than $1 \mathrm{Cu}$ cell; $1 \mathrm{Rs}+2 \mathrm{M}$ vein angulate; $2 \mathrm{Cu}+\mathrm{cu}$-a vein bi-angulate; nebulous $3 \mathrm{Cu}$ vein absent; nebulous $2 \mathrm{~A}$ vein absent; stigma developed, with distal margin convex; Rs+r-rs vein slightly curved forward, rising at distal margin of stigma.

Legs. Protibia short, $1.5 \times$ first tarsomere length, with protibial spur long, longer than half length of first tarsomere. Metacoxa with dorsal expansion, but without ventral one. Tarsomeres I-IV conical, progressively shorter distad, with short spines; claw simple and arched, base with only strong tooth; arolium simple, angulate, and slender.

Metasoma. Metasoma 1.6× longer than wide; tergites I-VI and sternite I coriaceous and without lateral pilosity; sternites III-VI polished; with sparse setae at posterior margin of tergites II-VI. Hypopygium wider than long, with anterior margin unilobate, anterior corner angulate, lateral margin convergent posterad, and its lateral margin straight.

Genitalia (Fig. 4A-C). Dorsal arm of paramere longer than ventral arm, "S"-shaped, and with basal margin narrow; ventral arm slender, with apex densely hairy, and inner margin straight. Basivolsella with cuspis bi-ramous, arms slightly indistinct, ventral arm not reaching apex of dorsal arm, slender, with apex rounded, dorsal arm wide and with apex rounded. Aedeagus slender and not reaching paramere apex level, with pair of apical lobes touching each other; with apical margin rounded, lateral of margin of basal portion slightly convex; apodeme divergent, base curved laterad; genital ring ventrad.

\section{Remarks}

This species is similar to Bradepyris proximus (Kieffer, 1906) in having the malar space parallel, the antenna with pubescence medium, the ocelli very small and the mesoscutum with notauli narrow and deep. However, the head of B. jordanicus sp. nov. is longer than wide, the antennae have sparse pubescence, the eyes are small, the pronotal disc is as long as wide, the mesoscutum is shorter than the mesoscutellum, the propodeal disc lacks a longitudinal ridge between the median and inner discal carinae and a sublateral carina is present, whereas B. proximus has the head as long as wide, the antennae with have dense pubescence, the eyes are large, the pronotal disc is shorter than wide, the mesoscutum is as long as the mesoscutellum, the propodeal disc has a longitudinal ridge between the median and inner discal carinae and a sublateral carina is absent. 


\title{
Distribution
}

Jordan.

\author{
Bradepyris baleariensis sp. nov. \\ urn:1sid:zoobank.org:act:8DBF1424-F4F6-4E17-989A-E91B1C2F157A
}

Figs 3A-D, 4D-E

\section{Diagnosis}

Head as long as wide, with malar space shorter than vertex-ocular line; clypeus with median lobe delimitated and rounded, median clypeal carina inclined; antenna with pubescence, erect, sparse, and short; frons not foveolate; ocellar fovea present and wide; dorsal and ventral half of occipital carina high and with side striate. Mesosoma coriaceous, with pronotum with anterior corner angled, and posterior margin sinuous; mesoscutum longer than mesoscutellum. Propodeal disc with longitudinal ridge between median and inner discal carinae. Mesopleuron coriaceous; posterior oblique sulcus present, foveolate, and complete. Forewing with nebulous $2 \mathrm{Cu}$ vein present; hind wing with six distal hamuli. Mesotibia with distal spine. Metasoma with hypopygium wider than long, with anterior corner angulate. Genitalia with dorsal arm of paramere longer than ventral arm and club-shaped; cuspis with arms hardly distinct; aedeagus slender, with apex not reaching paramere apex, and with apical margin rounded; apodema divergent, with base straight.

\section{Etymology}

The specific epithet baleariensis refers to the provenance of the material.

\section{Material examined}

\author{
Holotype \\ SPAIN: ふ̄, Baleares, Marshall col. (HNHM).
}

\section{Description}

Body (Fig. 3A). $4.92 \mathrm{~mm}$ long, LFW $3.0 \mathrm{~mm}$.

Colours. Head and mesosoma dark castaneous, nearly black; antenna and mandible dark castaneous, palpi castaneous; legs dark castaneous, except tarsi castaneous; tegula dark castaneous; wings doublebanded with venation dark castaneous; metasoma dark castaneous.

HEAD (Fig. 3B). Head as long as wide and narrow in lateral profile. Malar space shorter than vertexocular line, one parallel to the other in dorsal profile. Mandible wide apically, lower margin straight, with four sharpened apical teeth, lower tooth longer than immediately upper teeth and wider than others. Palpi caliciform and cylindrical in cross section. Clypeus with median lobe delimitated and rounded, without lateral lobe; median clypeal carina inclined, complete, line-shaped in dorsal profile, and below torulus. Antennal foraminal distance less than antennal foramen diameter. Antenna with pubescence, erect, sparse, and short; scape curved and with same diameter across extension; pedicel longer than wide and rectangular; flagellomeres long, first flagellomere longer than pedicel and as long as others. Eye small, elliptical, and glabrous. Frons not foveolate. Ocellar triangle not compact, placed on posterior half of head; ocellar fovea present and wide; frontal angle of ocellar triangle right; ocelli small. Vertex convex. Dorsal and ventral half of occipital carina high and with side striate.

Mesosoma (Fig. 3C-D). Pronotum with anterior slope inclined in lateral profile; pronotal plate not foveolate, without plate sulcus; pronotal disc $0.83 \times$ as long as wide, coriaceous, trapezoidal, side straight, with anterior margin convex, anterior corner angled, and posterior margin sinuous; longitudinal pronotal 

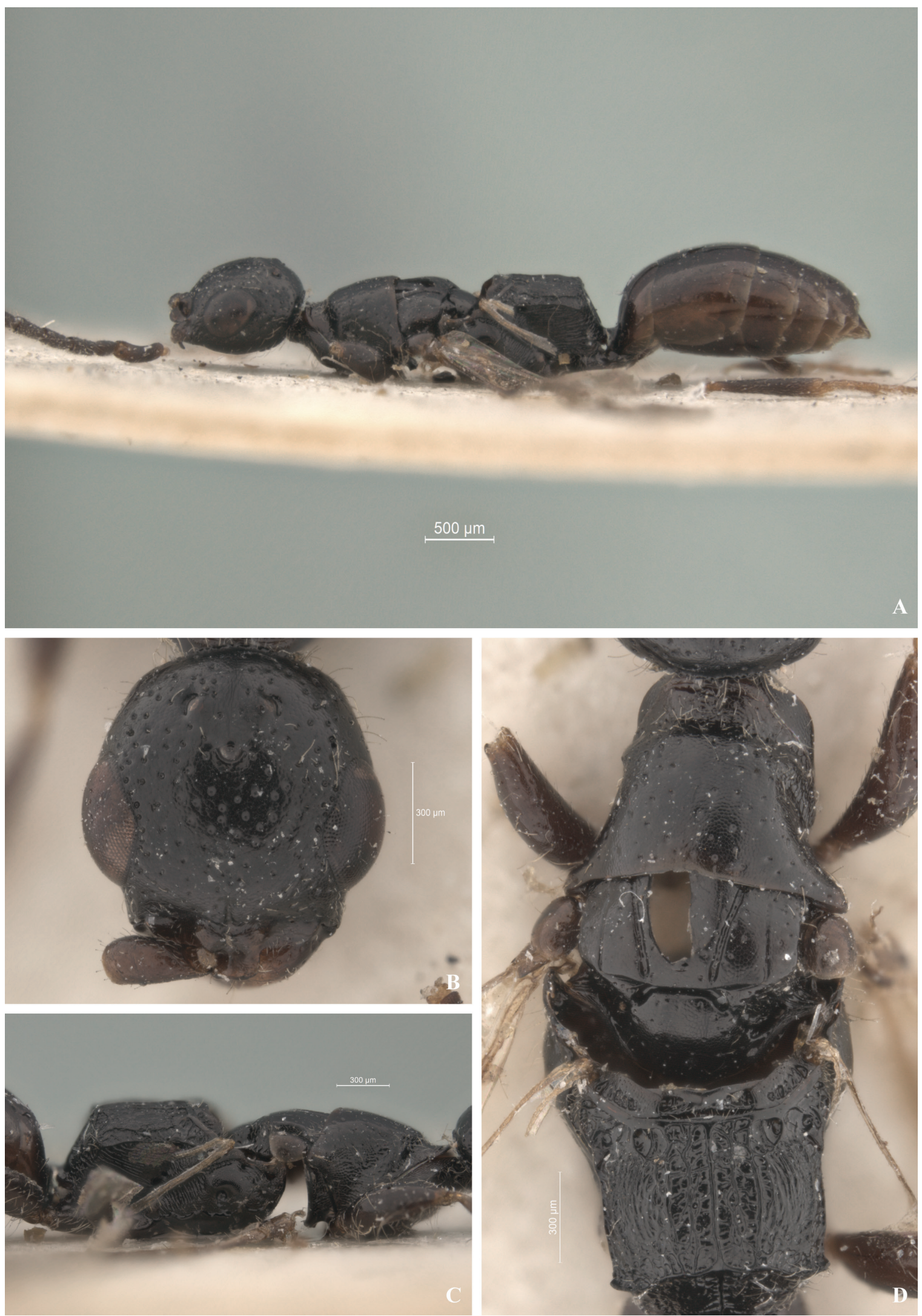

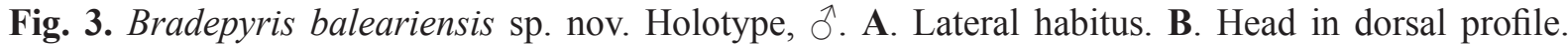
C. Mesosoma in lateral profile. D. Mesosoma im dorsal profile. 
sulcus absent. Mesoscutum coriaceous and longer than mesoscutellum; longitudinal mesoscutal sulcus absent. Notaulus complete, deep, narrow, and polished. Parapsidal signum incomplete, deep, and parallel. Axilla polished and shallow. Mesoscutum-mesoscutellar sulcus inconspicuous. Mesoscutellar sulcus narrow, arched, dilated at ends, and fused with axilla. Mesoscutellum shorter than wide and coriaceous. Metanotum overlapping lateral region of mesoscutellum. Propodeal disc $1.34 \times$ as long as wide medially, with central fovea fused with propodeal triangle fovea, with three carinae, median carina complete, with longitudinal ridge between median and inner discal carinae; sublateral and inner discal carina not fused anteriorly, inner discal carina complete; with sublateral carina, with lateral carina, posterior carina complete; spiracle elliptical; posterior spine absent. Declivity of propodeum weakly strigulate, with median carina and without lateral carina. Lateral surface of propodeum striate, without upper and posterior carinae. Mesopleuron coriaceous; with acropleural sulcus continuous with mesopleural suture; posterior oblique sulcus present, foveolate, and complete; mesopleural suture with inner margin striate. Propleuron with epicoxal sulcus shallow and polished.

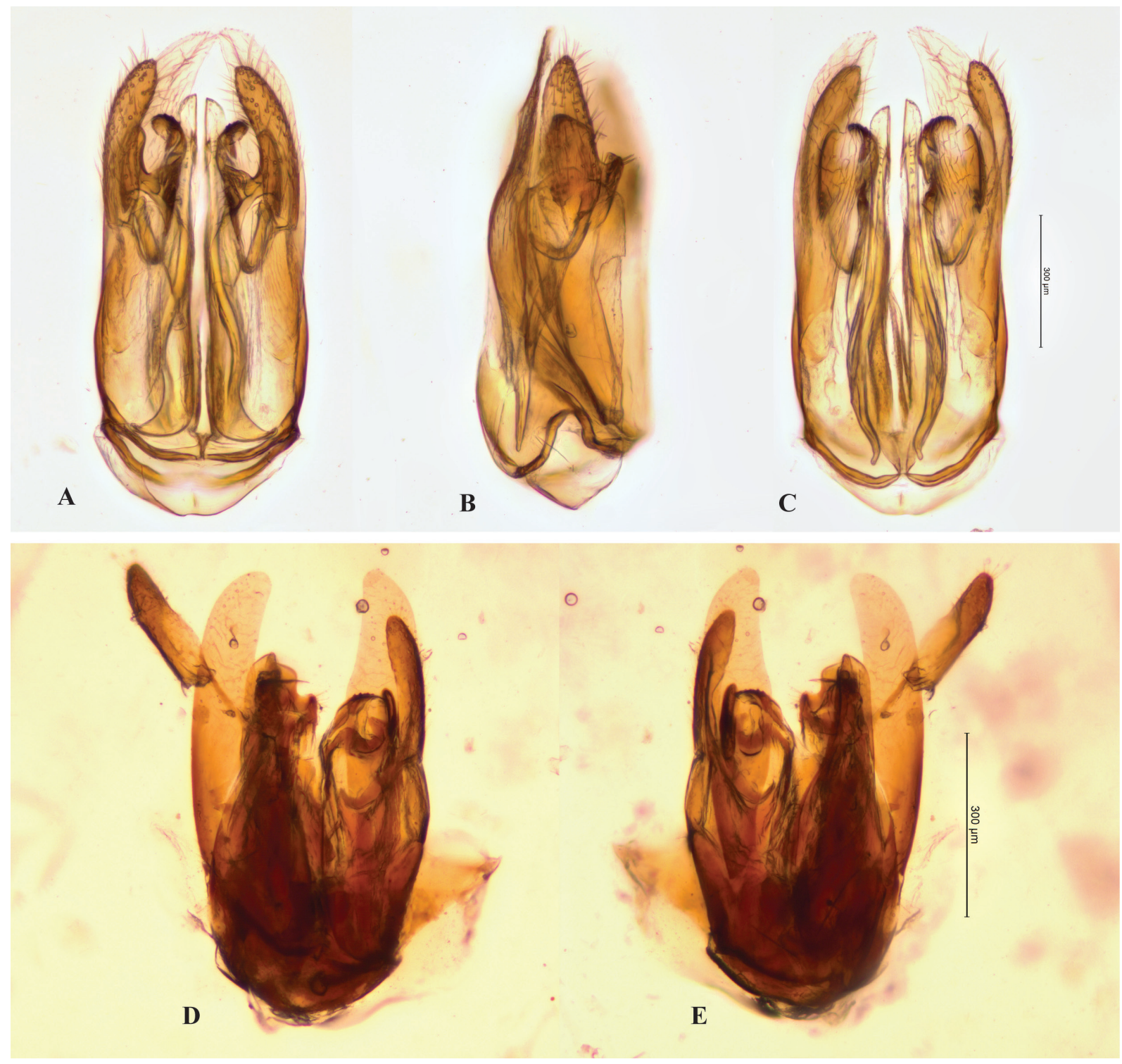

Fig. 4. Genitalia. - A-C. Bradepyris jordanicus sp. nov. A. Ventral view. B. Lateral view. C. Dorsal view. - D-E. Bradepyris baleariensis sp. nov. D. Ventral view. E. Dorsal view. 
WINGs. Forewing with $\mathrm{C}$ cell very narrow and longitudinally folded; $\mathrm{R}$ cell as long as $1 \mathrm{Cu}$ cell; $1 \mathrm{Rs}+2 \mathrm{M}$ vein angulate; $2 \mathrm{Cu}+\mathrm{cu}$-a vein biangulate; nebulous $2 \mathrm{Cu}$ vein present; stigma developed and with distal margin convex; Rs $+r-r s$ vein slightly curved forward and rising at distal margin of stigma. Hind wing with $\mathrm{Sc}+\mathrm{R}$ vein long; with six distal hamuli evenly separated one from another.

Legs. Protibia short, $1.5 \times$ first tarsomere length, and with protibial spur short, shorter than half length of first tarsomere. Metacoxa without dorsal and ventral expansion. Mesotibia with distal spine. Tarsomeres I-IV progressively shorter distad, with short spines, and cylindrical in cross section; claw simple, arched, and base with strong tooth only; arolium simple, slender, and with apex angulate.

Metasoma. Metasoma $1.7 \times$ longer than wide; tergites I-VI and sternite I coriaceous and without lateral pilosity, sternites III-VI polished; with sparse setae at posterior margin of tergites II-VI. Hypopygium wider than long, with anterior margin unilobate, anterior corner angulate, lateral margin convergent, and lateral margin straight.

Genitalia (Fig. 4D-E). Dorsal arm of paramere longer than ventral arm and club-shaped; ventral arm slender, with apex glabrous, and inner margin straight. Basivolsella with cuspis biramous, with arms hardly distinct; ventral arm not reaching apex of dorsal arm, slender, and with apex rounded; dorsal arm wide and with apex rounded. Aedeagus slender, with apex not reaching apex of paramere, with pair of apical lobes touching each other, and with apical margin rounded; lateral margin of basal portion convex; apodeme divergent, with base straight; genital ring ventrad.

\section{Remarks}

This species is similar to Bradepyris proximus (Kieffer, 1906) by having the head as long as wide, the malar space parallel, the antennae with pubescence medium, the ocelli very small, the mesoscutum longer than the mesoscutellum, with notauli narrow and deep, and the propodeal disc with a longitudinal ridge between the median and inner discal carinae. However, B. baleariensis sp. nov. has the antennae with spare pubescence, the eyes glabrous, the pronotal disc with the anterior corner angled and the posterior margin sinuous, the parapsidal signum conspicuous, the mesoscutellar sulcus with dilation at its ends, and the propodeal disc with a sublateral carina, whereas B. proximus has the antennae with dense pubescence, the eyes setose, the pronotal disc with the anterior corner rounded and the posterior margin straight, the mesoscutum as long as the mesoscutellum, the parapsidal signum inconspicuous, the mesoscutellar sulcus without dilation at its ends, and the propodeal disc without a sublateral carina.

\section{Distribution}

Spain (Baleares Islands).

\section{Brief comments on previously described species}

\section{Bradepyris apterus Kieffer, 1906}

This species is recorded from Tunisia. Its type, however, is lost so we couldn't examine it. Only a few characters were described in the literature: body black; body surface slightly coriaceous; pronotum 3.0× as long as mesonotum; propodeum without posterior spine; wings absent.

\section{Bradepyris armatus Kieffer, 1911}

This species is recorded from Morocco. We were able to examine the holotype female deposited at $\mathrm{BMNH}$, which has the following characteristics: body black; body surface slightly punctate; eye setose; pronotum $4.0 \times$ as long as mesonotum; mesoscutum shorter than mesoscutellum; propodeum with propodeal disc with median carina complete, posterior spine hardly distinct; wings absent. 


\section{Bradepyris dimorphus (Kieffer, 1911)}

This species is recorded from Morocco. We were able to examine the holotype female deposited at $\mathrm{BMNH}$, which has the following characteristics: body dark castaneous; head surface slightly punctate and mesosoma polished; eye setose; pronotum as long as mesonotum; mesoscutum as long as mesoscutellum; propodeal disc with longitudinal ridge between median and first pair of discal carinae and with sublateral carina; posterior spine absent; wings brachypterous.

\section{Bradepyris fuscipennis (Kieffer, 1906)}

This species is recorded from Algeria, Morocco, Spain and Israel. Its type, however, is lost so we couldn't examine it. Only a few characters were found in the literature: body black; body surface polished; head with surface coriaceous, sparsely punctate; eye setose; mesosoma with mesonotum shorter than pronotum; parapsidal signum deep; mesoscutellum as long as mesoscutum; propodeum without posterior spine; forewing bi-banded.

\section{Bradepyris inermis Kieffer, 1906}

This species is recorded from Morocco. We were able to examine the holotype male deposited at HNHM, which has the following characteristics: head with surface polished; mandible with four teeth at apex; eye protruding above level of head; ocelli with frontal angle of ocellar triangle right; malar space as long as vertex-ocellar line and parallel; pronotum and mesonotum with surface polished; mesonotum very short, about one-fifth of pronotum; propodeum coriaceous, central depression very narrow, with posterior spine very short and laterally orientated; wings absent; metasoma with tergites I-IV coriaceous; genitalia with ventral arm of paramere with inner margin emarginated, and aedeagus not reaching apex of paramere.

Bradepyris levis (Móczár, 1986) comb. nov.

This species is recorded from Gibraltar. We were able to examine the holotype female deposited at CNCI, which has the following characteristics: head with surface polished with sparse foveolation; clypeus with anterior margin rounded; ocelli very small, frontal angle of ocellar triangle acute; ocellar fovea present, but hardly distinct; pronotum longer than mesonotum and both with surface polished; parapsidal signum absent; metascutellum distinctly developed, with parallel margins, nearly as broad as central depression of propodeum; propodeum gibbous and polished, median carina hardly distinct, longitudinal ridge between median and first pair of discal carinae present, sublateral carina absent, posterior carina followed by foveae; mesopleuron with posterior oblique sulcus distinct; wings micropterous; metasoma with tergites I-II polished.

\section{Bradepyris micropterus Kieffer, 1910}

This species is recorded from Morocco. Its type, however, is lost so we couldn't examine it. Only a few characterisics could be extracted from the literature: body surface polished; ocelli small; pronotum as long as mesonotum; mesonotum sparsely punctate; propodeum as long as mesonotum, gibbous, polished, with central depression narrow, sublateral carina absent, posterior spine present and very short; wings micropterous; metasoma strongly arched and with tergites coriaceous.

\section{Bradepyris numidus (Marshall, 1906) comb. nov.}

This species is recorded from Algeria. Its type, however, is lost so we couldn't examine it. Only a few characterisics were found in the literature: body with surface polished, sparsely punctate; head with longitudinal sulcus; anterior ocellus larger than others; wings macropterous; mesoscutum with notaulus well impressed. 
Bradepyris pardoi (Móczár, 1984) comb. nov.

This species is recorded from Morocco. We were able to examine the holotype female deposited at HNHM, which has the following characteristics: body with surface polished, sparsely punctate; head with malar space narrower than vertex-ocellar line and parallel; clypeus with median lobe quadrate; frons with longitudinal sulcus present; ocelli very small; frontal angle of ocellar triangle acute; mesoscutum with parapsidal signum indistinct; propodeum polished, with central depression developed, sublateral carina inconspicuous, posterior spine absent; mesopleuron with posterior oblique sulcus distinct; wings brachypterous; metasoma with tergite II polished and tergites III-VI coriaceous.

Bradepyris proximus (Kieffer, 1906) comb. nov.

This species is recorded from Spain. We were able to examine the holotype male deposited at MNHN, which has the following characteristics: body coriaceous; head with antenna with sparse and long setae; clypeus with median lobe quadrate; eye protruding above level of head and setose; ocelli very small; frontal angle of ocellar triangle obtuse; pronotum short; mesoscutum with parapsidal signum hardly distinct; propodeum with central depression developed, sublateral carina absent, lateral carina hardly distinct, posterior spine absent; mesopleuron with posterior oblique sulcus distinct; wings macropterous; metasoma with tergites polished.

\section{Bradepyris squamifer Kieffer, 1911}

This species is recorded from Morocco. We were able to examine the holotype female deposited at $\mathrm{BMNH}$, which has the following characteristics: mesosoma with mesoscutum as long as mesoscutellum; parapsidal signum well impressed; propodeum with central depression developed, posterior spine absent; micropterous, with setae-like scales.

Bradepyris suarezi (Móczár, 1984) comb. nov.

This species is recorded from Morocco. We were able to examine the holotype female deposited at HNHM, which has the following characteristics: body with surface polished, sparsely punctate; head with malar space narrower than vertex-ocellar line and parallel; clypeus with median lobe quadrate and with anterior margin rounded; frons with longitudinal sulcus present; ocelli very small; frontal angle of ocellar triangle acute; parapsidal signum hardly distinct; notaulus well impressed; propodeum short and polished, central depression developed, sublateral carina absent, posterior spine hardly distinct; mesopleuron with posterior oblique sulcus distinct; micropterous; metasoma with tergites polished, tergite II sparsely punctate.

Bradepyris validithorax (Duchaussoy, 1916) comb. nov.

This species is recorded from Morocco. Its type, however, is lost so we couldn't examine it. Only a few characters were found in the literature: female: body with surface polished, sparsely punctate; head with malar space narrower than vertex-ocellar line and parallel; frons with longitudinal sulcus present; ocelli very small; pronotum longer than mesonotum; mesoscutum with parapsidal signum hardly distinct; notaulus well impressed; propodeum with central depression developed, sublateral carina present, posterior spine hardly distinct; brachypterous; mesotibia with distal spines; metasoma with tergites polished; male: body with surface polished, sparsely punctate; head as long as wide; antenna longer than head and mesosoma together; frons with longitudinal sulcus weakly impressed; ocelli very small; frontal angle of ocellar triangle right; mesosoma with pronotum shorter than mesonotum; mesoscutum longer than mesoscutellum; propodeum with central depression developed, sublateral carina present; mesopleuron with posterior oblique sulcus distinct; macropterous; metasoma with tergites polished; hypopygium longer than wide, posterior margin unilobate. 


\section{Key to the females of the species of Bradepyris}

1. Macropterous, wings reaching at least first segment of metasoma ......B. numidus (Marshall, 1906)

- Brachypterous or micropterous, wings reaching at most half of propodeum

2. Brachypterous, wings reaching at least anterior half of propodeum ............................. 3

- Micropterous, wings reaching at most length of mesoscutellum ..............................

3. Mesotibia with distal spine

B. validithorax (Duchaussoy, 1916)

- Mesotibia without distal spine

4. Anterior clypeal margin rounded; ocellar triangle in acute angle; propodeal disc with sublateral carina; metasoma not setose

B. pardoi (Móczár, 1984)

- Anterior clypeal margin truncate; ocellar triangle in obtuse angle; propodeal disc without sublateral carina; metasoma setose

B. dimorphus (Kieffer, 1911)

5. Pronotum as long as mesoscutum

B. micropterus Kieffer, 1910

- Pronotum $2-4 \times$ as long as mesoscutum

6. Forewing scaly, reaching posterior margin of mesoscutellum

B. squamifer Kieffer, 1911

- Forewing hardly distinct

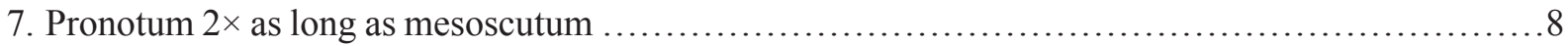

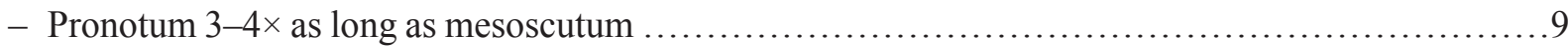

8. Propodeum with posterior spine

B. inermis Kieffer, 1906

- Propodeum without posterior spine

B. suarezi (Móczár, 1984)

9. Head strongly and densely punctate; mesosoma and metasoma sparsely punctate

B. apterus Kieffer, 1906

- Head slightly and sparsely punctate; mesosoma and metasoma not punctate

10. Body sparsely setose; metasomal tergites coriaceous

B. armatus Kieffer, 1911

- Body densely setose; metasomal tergites polished

B. levis (Móczár, 1986)

Key to the males of the species of Bradepyris

1. Micropterous, wings reaching at most length of mesoscutellum

B. inermis Kieffer, 1906

- Macropterous, wings reaching at least first segment of metasoma .2

2. Mesoscutum shorter than mesoscutellum .....................................................

- Mesoscutum longer than mesoscutellum ................................................... 4

3. Frons weakly foveolate; eye pubescent and large

B. fuscipennis Kieffer, 1906

- Frons not foveolate; eye glabrous and small B. jordanicus sp. nov.

4. Antennal pubescence dense; propodeal disc without sublateral carina

B. proximus Kieffer, 1906

- Antennal pubescence spare; propodeal disc with sublateral carina

B. baleariensis sp. nov.

\section{Discussion}

During our analysis, we established that the genera Bradepyris, Pseudomesitius and Triglenus do not have enough characteristics to distinguish them from each other, as Argaman (2003) argued. These 
characteristics are, in fact, only diagnostic at the species level. There was, therefore, no reason to maintain three separate genera and, consequenstly, Pseudomesitius and Triglenus are proposed as junior synonyms of Bradepyris. The genus is redescribed and its species are commented upon. Furthermore, we were able to establish the distribution of this genus as being restricted to the Mediterranean region, an unusual distribution and not recorded for genera of the Bethylidae before. It turns out that the species of Bradepyris form a consistent group and further studies will shed more light on relationships within the Bethylidae.

\section{Acknowledgments}

We are grateful to Gellért Puskás for the loan of the material studied and to Claire Villeman for the loan of the holotype of Bradepyris proximus. This work was supported by grant $\mathrm{CNPq} / \mathrm{FAPES} / \mathrm{CNPq}$ PRONEX\#52263010/2011, by FAPES for the fellowships provided to the first author, grant \#020/2012, and by CNPq for the fellowships provided to the second author, grant \#151153/2013-2.

\section{References}

Argaman Q. 2003. Generic synopsis of Mesitinae Kieffer, 1914 (Hymenoptera: Bethylidae). Entomofauna 24: 61-96.

Barbosa D.N. \& Azevedo C.O. 2009. Laelius Ashmead (Hymenoptera, Bethylidae) from Madagascar, with description of two new species. Zootaxa 2171: 1-14.

Barbosa D.N. \& Azevedo C.O. 2011. Order Hymenoptera, family Bethylidae, Subfamily Mesitiinae. In: van Harten A. (ed.) Arthropod Fauna of the UAE. Volume 4: 375-404. Dar Al Ummah Printing, Publishing, Distribution \& Advertising, Abu Dhabi.

Dallwitz M.J., Paine T.A. \& Zurcher E.J. 1993. User's Guide to the DELTA System: a General System for Processing Taxonomic Descriptions, 4th edn. Available from http://delta-intkey.com/www/uguide. htm [accessed 20 Aug. 2006]

Duchaussoy A. 1916. Nouveaux Bethylides de l'Afrique du nord et de l'Europe orientale (Hyménoptères). Bulletin de la Société d'Histoire Naturelle d'Afrique du Nord 7: 109-126.

Duporte E.M. 1965. The lateral and ventral sclerites of the insect thorax. Canadian Journal of Zoology 43: 141-154. http://dx.doi.org/10.1139/z65-012

Evans H.E. 1964. A synopsis of the American Bethylidae (Hymenoptera, Aculeata). Bulletin of the Museum of Comparative Zoology 132: 183-189. Available from http://www.biodiversitylibrary.org/ page/4315706 [accessed on 6 Nov. 2013]

Gibson G.A.P. 1986. Mesothoracic skeletomusculature and mechanics of flight and jumping in Eupelminae (Hymenoptera, Chalcidoidea: Eupelmidae). The Canadian Entomologist 118: 691-728. http://dx.doi.org/10.4039/Ent118691-7

Kieffer J.J. \& Marshall T.A. 1904-1906. Proctotrypides. In: André E. (ed.) Species des Hyménoptères d'Europe \& d'Algerie. Tome IX: 551pp. Librairie Scientifique, A. Hermann, Paris. [Publication dates of the different parts: pages 1-64 1st January 1904; 65-144 1st April 1905; 145-288 1st November 1905; 289-368 31st January 1906; 369 until the end 1st October 1906]. http://www.biodiversitylibrary.org/ item/41011

Mikó I., Vilhelmsen L., Johnson N.F., Masner L. \& Pénzes Z. 2007. Skelotomusculature of Scelionidae (Hymenoptera: Platygastroidea): Head and mesosoma. Zootaxa 1571: 1-78.

Móczár L. 1970. Mesitiinae of world with new genera and species. I. (Hymenoptera: Bethylidae). Acta Zoologica Academiae Scientiarum Hungaricae 16: 175-203. 
Richards O.W. 1977. Hymenoptera. Introduction and key to families. In: Handbooks for the Identification of British Insects: 98. Royal Entomological Society of London, Queens Gate, London.

Ronquist F. \& Nordlander G. 1989. Skeletal morphology of an archaic cynipoid, Ibalia rufipes (Hymenoptera: Ibaliidae). Entomologica Scandinavica 33: 1-60.

Manuscript received: 19 August 2015

Manuscript accepted: 8 October 2015

Published on: 10 November 2015

Topic editor: Koen Martens

Desk editor: Kristiaan Hoedemakers

Printed versions of all papers are also deposited in the libraries of the institutes that are members of the EJT consortium: Muséum national d'Histoire naturelle, Paris, France; Botanic Garden Meise, Belgium; Royal Museum for Central Africa, Tervuren, Belgium; Natural History Museum, London, United Kingdom; Royal Belgian Institute of Natural Sciences, Brussels, Belgium; Natural History Museum of Denmark, Copenhagen, Denmark. 